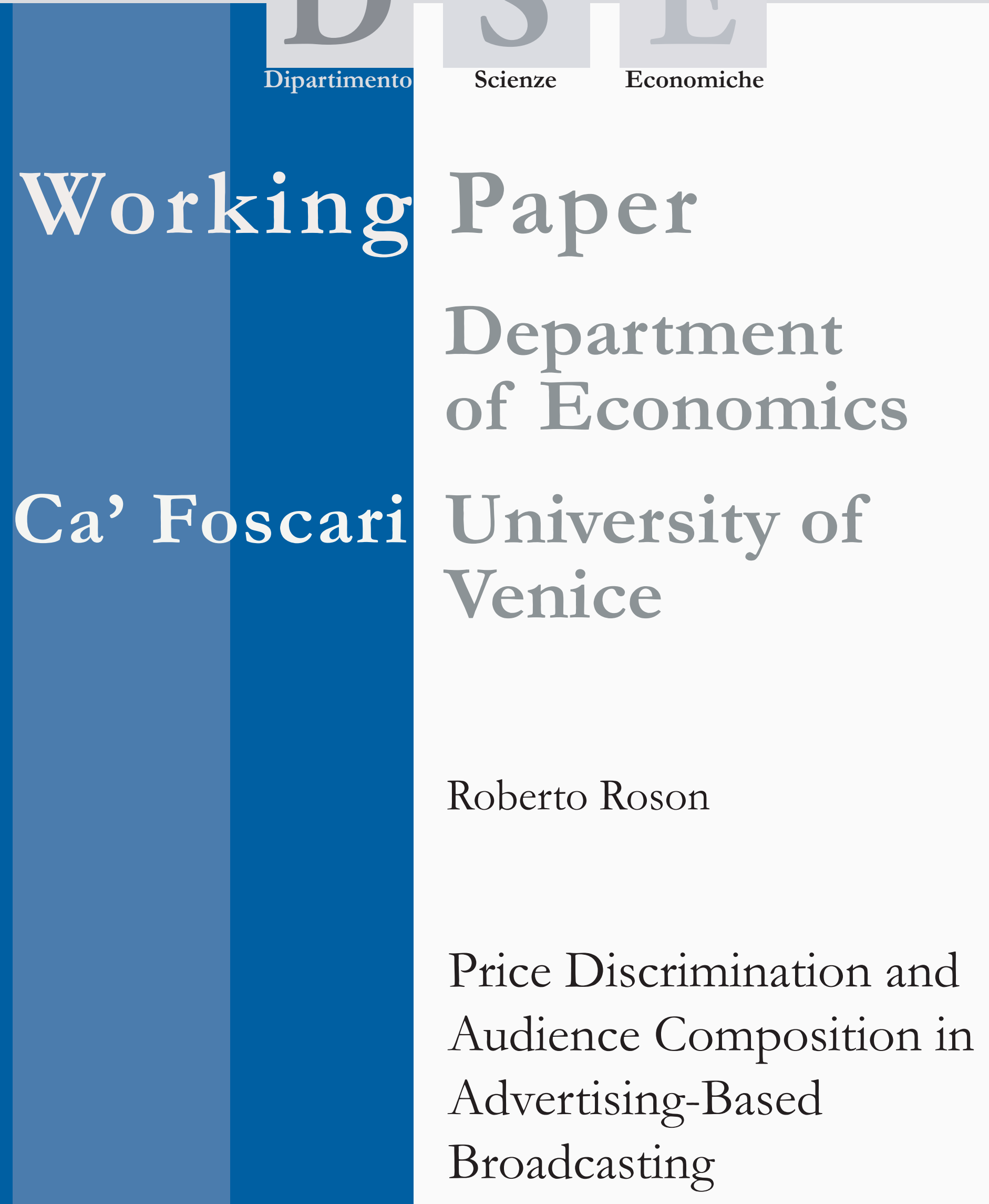


Working Papers

Department of Economics

Ca' Foscari University of Venice

No. $07 / \mathrm{WP} / 2007$

ISSN 1827-3580

\title{
Price Discrimination and Audience Composition in Advertising-Based Broadcasting
}

\author{
Roberto Roson \\ Università Ca'Foscari di Venezia
}

First Draft: May 2007

\begin{abstract}
Traditionally, media like TV and radio, but also the Internet, have been characterized by free access (by consumers having the necessary hardware), with services supported through advertising revenues. Profitability in these markets depends on the capability of attracting audience. Strategic choices, however, also depend on the relationship with the dual market for advertising services.

In this paper, a model is introduced, which has two distinguishing features. First, the multidimensional nature of competition in media markets is acknowledged, through explicit modeling of vertical and horizontal differentiation. Second, the price of advertising depends on the expected audience composition, not simply on its magnitude.

It also depends on the broadcasters' capability of effectively price-discriminate among advertising customers.

It is found that market equilibria depend on a number of critical factors: the amount and type of price discrimination in advertising, the correlation between formats and audience composition, the relative profitability of the different market segments, and diseconomies of scale in program quality.
\end{abstract}

\section{Keywords}

Advertising, Media Industries, Broadcasting, Price Discrimination, Television, Radio, Differentiation

\section{JEL Codes}

L82, M37

Address for correspondence: Roberto Roson

Department of Economics Ca’ Foscari University of Venice Cannaregio 873, Fondamenta S.Giobbe 30121 Venezia - Italy Phone: (++39) 041234

Fax: $(++39) 0412349176$ e-mail: roson@unive.it

This Working Paper is published under the auspices of the Department of Economics of the Ca' Foscari University of Venice. Opinions expressed herein are those of the authors and not those of the Department. The Working Paper series is designed to divulge preliminary or incomplete work, circulated to favour discussion and comments. Citation of this paper should consider its provisional character.

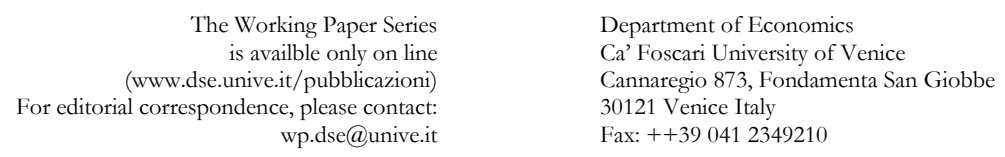

The Working Paper Series

wp.dse@unive.it
Department of Economic

Cannaregio 873, Fondamenta San Giobbe

Fax: ++390412349210 


\section{Introduction}

Traditionally, media like TV and radio, but also the Internet, have been characterized by free access (by consumers having the necessary hardware), with services supported through advertising revenues. Although other business models have emerged (e.g., pay-TV, pay-per-view, etc.), this is still the distinctive market characteristic in many media industries.

Profitability in these markets depends on the capability of attracting audience. Larger audiences (viewers, listeners, "eyeballs") affect the value of advertising services, therefore the revenue of TV or radio stations, or Internet portals. Competitors fight for audience through horizontal and vertical product differentiation. For example, TV channels make strategic decisions about the format, scheduling and quality of the programs: the competitive game is, therefore, intrinsically complex and multidimensional.

Strategic choices, however, also depend on the relationship with the dual market for advertising services. The view that channels and advertisers aim at maximizing audience is quite simplistic. Market segmentation is important: advertisers want to know who is the typical viewer of a certain TV program (Thompson (1989)). Advertisers may want to place their spots inside certain programs, rather than others. They may also support certain TV productions, because they could have some cultural influence, suggesting "lifestyles" consistent with the products to be advertised.

Price discrimination in the market for advertising is also important. The law of one price does not apply if broadcasters may affect the willingness to pay of advertisers through their programming choices.

In the literature on media market competition, this bilateral relationship between advertising and media industries is often neglected (see, however, Rosse (1970), Dertouzos and Trautman (1990), Blair and Romano (1993), Rysman (2004)). Many models simply assume that there exist a constant return per viewer/listener for the competing channels, so that audience maximization is the main objective in advertising-supported media industries.

In this paper, a new model is introduced, which has two distinguishing features. First, the multidimensional nature of competition in media markets is acknowledged, through explicit modeling of vertical and horizontal differentiation. In the context of horizontal differentiation, it is recognized that there are, typically, a finite set of alternative "formats" available, for example for TV programs. Second, the price of advertisement depends on the expected audience composition, not simply on its magnitude. It also depends on the broadcasters' capability to price-discriminate effectively among advertising customers.

The paper is organized as follows. The next section illustrates the existing literature on media market competition, and discusses the relation with the model proposed here. The model structure 
and some results, for various market configurations, are presented in section 3. The following section discusses the policy implications, possible extensions and limitations of the model. A final section concludes.

\section{Relation with Previous Literature}

The literature on media market competition has focused on specific issues. The classic reference is Steiner (1952), who considered the problem of program duplication in a radio industry with advertising-based revenues. He found the striking result that monopoly may be superior than competition, as wasteful program duplication may be avoided.

Steiner's approach, later adopted by other authors (e.g., Beebe $(1977)^{1}$, Spence and Owen $\left.(1977)^{2}\right)$, is peculiar because there exist a discrete set of program typologies, and consumer preferences are mapped to this set. On the other hand, programming may be regarded as an example of product differentiation, and maximal differentiation should be expected as a natural outcome, since differentiation allows the achievement of local market power.

The standard approach in the product differentiation literature is based on some variant of Hotelling's localization model, which considers a continuum space. In a Hotelling duopoly, identical localization choices emerge if price competition is ruled out. If price, or quality, competition is considered in a two-stage game, then differentiation is maximal. This would mean, in media markets like TV or radio, that program duplication would never occur. To restore the duplication result, two additional hypotheses are needed: (1) that consumer preferences are not uniformly distributed (concentration of preferences), (2) that localization alternatives are a finite, discrete set. Although the Steiner modeling approach can be regarded as an example of the latter case, other authors have recently opted for a more conventional methodology, based on localization in continuum space. This provides two main advantages. First, calculus can be used, instead of more complex combinatorial methods. Second, a richer array of consumer characteristics and competition instruments can be considered.

For instance, Papandrea (1997) uses a Salop-like model of monopolistic competition, in which the concept of "breadth of appeal" can be introduced, to distinguish between popular and "niche" programs. Berry and Waldfogel (1999a) empirically assess the classic problem of socially inefficient market entry, in US regional radio markets. Berry and Waldfogel (1999b) adopt the same approach to investigate the issue of spatial pre-emption as a market barrier.

Bourreau (2002) explicitly compares "mimicking” strategies in TV programming (equivalent to

1 He found that, if consumers have second-best alternatives, monopoly may be worse than competition, because of the tendency of providing "common denominator" programs. Program variety may be too little.

2 They compare pay-TV with free, advertising based TV. They identify sources of market inefficiency in the two cases. 
identical localization in the space of program characteristics) with counter-programming (maximal differentiation), in the two regimes of pay-TV and advertising support. He founds that program differentiation is maximal in the pay-TV, whereas mimicking may emerge in advertising supported $\mathrm{TV}$, but only if the cost of program quality is relatively high.

Anderson and Coate $(2000,2005)$ consider the possibility that the amount of advertising is freely chosen by the broadcasting firms, assuming that there is a nuisance cost imposed on consumers by advertising. These authors compare the social optimum with the market equilibrium, in the two cases of pay-TV (or equivalent system, for other media) and free access with advertising support. Under pay-TV, or equivalent regime, the market becomes two-sided, with negative network externalities on one side (Roson (2005)).

An interesting aspect of these latter works is that the price of advertising services is explicitly derived in terms of market equilibrium, instead of assuming, as it is generally done, that there exist a fixed, exogenously given, unit revenue per viewer (listener, etc.). However, because of the simplifying assumptions adopted in that model, a single price (per viewer) for advertising services emerges. This implies that, in a free access system entirely based on advertising, maximizing revenue means maximizing audience.

On the other hand, it is clear that actual markets for advertising services are much more complex than that suggested by most media competition models. ${ }^{3}$ Prices for advertising are not flat; rather, various kinds of price discrimination mechanisms are usually at work. Also, customers of advertising services in media like TV, radio, Internet, etc., are not simply interested in getting the largest audience, but they are also interested in the type of audience. By doing so, they naturally influences programming and scheduling, especially under a free access, advertising supported regime. For example, in a recent report (Ofcom (2004)), it is stated:

\footnotetext{
In the market for TV advertising, advertisers purchase opportunities to present their products to TV viewers from the commercial broadcasters, often through the use of intermediary media buyers. Typically, advertisers will pay according to the number of impacts that are achieved for their target audience (or, in some cases, expected number to be achieved), and the price negotiations begin at the prices indicated on the relevant advertising 'rate card', expressed as 'cost per thousand' impacts. But the true price paid is determined through negotiations that determine a discount on the rate card, considering many factors (including deal size, share of expenditure on the channel, nature of the product and timing of the advertisements).

(...)

The increasing number of channels is likely to result in lower average audiences per channel ('audience fragmentation'), which may adversely affect the value of advertising (advertisers are thought to commonly prefer larger audiences as this helps to reduce duplication of advertising impacts on the same individuals). On the other hand, more channels could produce better audience segmentation (by defined audience type), that could actually increase the value of advertising (as a defined audience group can be reached).
}

3 Bagwell (2003) provides a very comprehensive survey of the theoretical and empirical literature on advertising. 
Introducing a more realistic representation of advertising in media competition models is not easy, as competition in media industries is already characterized by complex, multidimensional strategies. Broadcasting channels, for example, compete in access prices (if possible), advertisement prices, quality of programs, format and variety of programs, scheduling, etc. Capturing all these dimensions in a single theoretical model is practically impossible.

Nonetheless, the basic nature of the demand for media services as derived from the demand for advertising should explicitly be recognized: program content and advertising are complementary services. In turn, advertising and goods in the final markets are also complementary.

The model we present in the next section can be regarded as a step in this direction. ${ }^{4}$ Channel competition is multidimensional: choice of format type within a discrete set of format alternatives, horizontal differentiation within the format, quality choice. Consumers/viewers are not homogeneous, and there exist a correlation between program type and audience composition, influencing the willingness to pay of advertisers. Also, various kinds of price discrimination in the market for advertising are taken into account.

\section{The Model}

\subsection{Basic Setting}

There are three types of agents in the model: "many" consumers, three advertisers and producers, one or more broadcasters.

Consumers belong to three categories, differentiated on the basis of their program preferences and consumption behavior. Just for illustrative purposes, let us call them "professionals" (P), "housewives" $(\mathrm{H})$ and "teenagers" $(\mathrm{T})$. Each group contains a number $\eta_{i}$ of individuals, each one buying an average number of $v_{i}$ units of a group-specific good, for example: professionals buy computers, housewives buy hairdryers, and teenagers buy music CDs. However, all purchases take place only if consumers get to know about the existence of goods on the market, which may occur after viewing or listening an ad.

There is a single producer for each good, getting a unitary profit margin $\pi_{i} \quad$ (price - production cost). Therefore, the "value" of market $i$ is:

$$
V_{i}=\eta_{i} u_{i} \pi_{i}
$$

Suppose that $V_{P}>V_{H}>V_{T}$. Without loss of generality, normalize $V_{H}=1$, and assume that the

4 A model sharing the same perspective is in Dukes (2004). There are oligopolistic markets in media (advertisingbased) and products. Consumers are ideally located in two circumferences, for product and program types. There are nuisance costs of advertising, but advertising is informative (consumers can access one product only if reached by specific advertisement, diffused by some station). Other models model which paying explicit attention to the ability to target advertising to specific groups of consumers are Grossman and Shapiro (1984), Chandra (2006). 
three markets are "equally spaced" in terms of value: $V_{P}=1+\delta, V_{T}=1-\delta$. This is a convenient hypothesis, which allow us to express the value spread in terms of a single parameter (ठ).

Broadcasters have perfect information. Therefore, they could fully extract the producers' rent, by charging, for an advertisement of good type $i$ in $\operatorname{program} j$, up to:

$$
p_{i}^{j}=\phi_{i}^{j} V_{i}
$$

where $\phi_{i}^{j}$ is the share of $i$-consumers selecting $\operatorname{program} j$.

Consumers may watch the TV, listen to the radio, or generally access a broadcasting media. This access is free of charge, and there are no nuisance costs associated with the possible existence of advertising. If more program types are available, each agent can choose to watch (listen, etc.) one type of program. There are, at most, three program types. Merely for illustrative purposes, let us call them "sport" (S), "comedy" (C) and "music" (M). Any channel can broadcast only one type of programs. ${ }^{5}$ All agents can also decide to undertake an alternative activity, providing an average utility of $\mu$.

An agent $i$ selects the program type $j$, or the alternative activity, on the basis of the maximum expected utility, $U$. If there are more channels broadcasting the same type of programs, one specific channel is chosen, but only after selecting the program type. Individual utility is given by the sum of two components: a "group" utility, $u$, based on expected utility, and an idiosyncratic component $\epsilon$, i.i.d., accounting for individual differences within the same group of people:

$$
U_{i}^{j}=u_{i}^{j}+\varepsilon_{i}^{j}
$$

Expected utility for the outside option is $\mu$. Utility for a broadcast type $j$ is given by the expected quality of the programs, multiplied by a "correlation factor" $\mathrm{Y}$. In turn, the perceived quality is defined as the difference between "intrinsic" quality of the programs and a nuisance cost, proportional to the number $n$ of spots realized in the program:

$$
u_{i}^{j}=\gamma_{i}^{j} q^{j}=\gamma_{i}^{j}\left(\widetilde{q^{j}}-\kappa n\right)
$$

The parameter $\gamma$ expresses the tendency, for a particular group of people, of being "relatively more attracted" by one specific type of programs. This factor is normally set to one, except when professionals evaluate sport programs $(i=P, j=S)$, or housewives evaluate comedies $(i=H, j=C)$, or teenagers evaluate music programs $(i=T, j=M)$. In these cases, $\gamma \geq 1$. Therefore, although individuals do make different choices, even within the same group, professionals tend to watch sport programs relatively more than the rest, housewives tend to watch more comedies, and teenagers tend to watch more music programs, ceteris paribus. This parameter plays an important

5 This does not mean that channels must have only one type of program (e.g., "all news"). This hypothesis could be interpreted as focusing on one specific time segment (e.g., "prime time on Tuesday"). 
role in the model, in association with the parameter $\delta$. The latter tells us how different, and relatively important, consumers are from the viewpoint of advertisers. The parameter $\gamma$, on the other hand, tells us how much correlation there is between program types and audience composition. Therefore, for example, if sport programs are mostly seen by professionals, and professionals can buy expensive ${ }^{6}$ computers, an ad in a sport program will be valued more than an ad in a music show, which is mostly seen by low-spending teenagers.

The probability for a program type of being selected is the probability that the associated utility $U$ is higher than the utility associated with alternative program types, or with the outside option. This probability is increasing in the expected quality of the programs inside the class, and decreasing in the quality of programs outside the class. Furthermore, since there are "many" agents in every group, the probability can also be interpreted as the share of people, in each group, watching programs of a particular type.

The specific form that this share function $(\Phi)$ can take depends on the distribution of the parameter $\epsilon$. The obvious choice here is assuming that the distribution is exponential (Weibull-Gumble), so that a logit expression is readily obtained:

$$
\Phi_{i}^{j}=\frac{\exp \left(\gamma_{i}^{j} q^{j}\right)}{\exp (\mu)+\exp \left(\gamma_{i}^{j} q^{j}\right)+\exp \left(\gamma_{i}^{k} q^{k}\right)+\exp \left(\gamma_{i}^{l} q^{l}\right)}
$$

In the expression above, $\gamma$ is 1 in two out of the three combinations, and the expected quality for a category in which there are no broadcasting channels can be taken as "minus infinity" (a very high negative number).

Channels are differentiated in three dimensions: type, intra-type horizontal differentiation and vertical (quality) differentiation. Differentiation choices are the only competition strategies for broadcasters, who aim at maximizing profits, obtained by selling advertising to producers of final goods.

Inside each category of programs, both channels and consumers are ideally located in a circle of unitary perimeter. Each "type" corresponds to a different circle and channels within the type are located within each separate circle. Consumers discover their exact location only after selecting one program type. All locations are equally probable ex-ante, meaning that consumers are homogeneously distributed ex-post inside the circle.

If there is more than one channel for a type, a consumer chooses the channel providing the maximum sub-utility $w$, expressed as the difference between program quality $q$ (provided by channel $c$ in type $j$ ) and squared distance between the consumer and the channel in the circle $(d)$ :

$$
w_{i}^{j}=\max \left[q_{c}^{j}-t\left(d_{i-c}^{j}\right)^{2}\right]
$$

6 It would be more correct to say "profitable" computers. 
where $t$ is a "transport cost" parameter. Therefore:

$$
q^{j}=E\left(w_{i}^{j}\right)=\int_{0}^{1} w_{i}^{j}
$$

Quality is expensive to produce, and marginal costs are increasing in quality levels. In most of the numerical examples shown later in the paper, it is assumed that marginal costs are linearly increasing, with a unitary slope factor (quadratic costs).

Consumers, producers and broadcasters play a game, whose timing is as follows:

1. Broadcasters choose where to locate the channels they own, in terms of type, horizontal and vertical differentiation. ${ }^{7}$ The number of channels for all broadcasters is given. ${ }^{8}$ If several broadcasters are present, their choices are not coordinated, which means that this stage can be interpreted as a Nash sub-game.

2. Consumers decide which program type to watch, or doing an alternative activity. Expected utility of the programs by type is known. The latter also depends on the number of channels available within each category.

3. Consumers discover their location in terms of intra-type preferences, and one channel is finally chosen.

4. Broadcasters set prices for ad slots, and sell advertising services to producers.

5. Consumers buy goods, discovered through advertising, on the markets.

\subsection{Preliminary Findings}

This section establishes some results, which will be used later in the paper.

Lemma 1. Two independent channels maximize profits by locating the farthest away from each other in the circle.

Proof. See Appendix. This result is standard in the literature, when applied to price competition and convex "transport" costs in a circle.

Lemma 2. Expected utility for a program category, at given quality levels and with two channels, is maximized when the channels are located the farthest away form each other in the circle.

Proof. Trivial. Direct consequence of convexity of sub-utility $w$ in distance.

Lemma 3. The market area in the unitary circle, for a channel with quality $q_{1}$ facing another channel

with quality $q_{2} \leq q_{1}+t / 4$ is $2\left(\frac{1}{4}+\frac{q_{1}-q_{2}}{t}\right)$.

7 Quality is set after location in the circle.

8 It could have been set by a market regulator beforehand. 
Proof. Assume, without lack of generality, that the first channel is located in zero and the second one is located in $1 / 2$. Solve for $x$, and multiply by two: $q_{1}+t x^{2}=q_{2}+t(1 / 2-x)^{2}$.

Lemma 4. Expected/average utility for a program type in which one channel with quality $q$ is active is $q-t / 12$.

Proof. Assume, without lack of generality, that the channel is located in zero. Compute $2 \int_{0}^{1 / 2} q-t x^{2} d x$

Lemma 5. Expected/average utility for a program type in which one channel has quality $q_{1}$ and a second one has quality $q_{2} \leq q_{1}+t / 4$ is: $\quad \frac{\left(q_{1}-q_{2}\right)^{2}}{t}+\frac{q_{1}+q_{2}}{2}-\frac{t}{48}$. Therefore, if $q_{1}=q_{2}=q$, expected utility is $q-t / 48$.

Proof. Assume, without lack of generality, that the first channel is located in zero and the second one is located in $1 / 2$. Compute $2 \int_{0}^{1 / 4+\left(q_{1}-q_{2}\right) / t} q_{1}-t x^{2} d x+2 \int_{0}^{1 / 4+\left(q_{2}-q_{1}\right) / t} q_{2}-t x^{2} d x$.

\subsection{Case \#1: Monopolistic broadcaster with one channel}

Consider the case of a single broadcaster, owning one channel. What type of programs will this channel show? If the broadcaster maximizes advertising revenue, this will be a sport channel, since professionals have a tendency to watch sport programs, and having a larger share of professionals in the audience can ensures higher profits in selling advertising spots.

However, some housewives and some teenagers will also watch the only available channel: this could allow the realization of advertisement for hairdryers and CDs.

We can distinguish here between two regimes, depending on whether or not the monopolistic broadcaster can implement price discrimination in the advertising market. Price discrimination means that prices for ad spots can be different. Since profits indirectly obtained through advertising are known, the broadcaster can charge up to $\phi_{P}^{S} 1+\delta$ for a computer spot, $\phi_{H}^{S} 1$ for a hairdryer spot, $\phi_{T}^{S} 1-\delta$ for a CD spot. Producers surplus is fully extracted, and the broadcaster profit coincides with the global social welfare, net of the consumers' utility of watching/listening programs.

The broadcaster maximizes profit, which can be expressed as the difference between a revenue function and a cost function. Under price discrimination, the revenue function is given by the sum of products between audience levels and spot prices, for the three groups of viewers ${ }^{9}$ :

9 An implicit assumption here is that the number of spots per program is unrestricted. 


$$
R(q)=\frac{\exp (\gamma q)}{\exp (\mu)+\exp (\gamma q)}(1+\delta)+\frac{\exp (q)}{\exp (\mu)+\exp (q)}(1+1-\delta)
$$

And, because of Lemma 4, if $q_{1}$ is the quality of programs in channel $1, q=q_{1}-t / 12$.

If the broadcaster cannot price discriminate, she sets prices for ad spots, independently of their content, but possibly proportional to the expected number of (relevant) viewers. Since the indirect demand for advertising is discontinuous at the three levels of willingness to pay, there are three options available for profit maximization:

1. Setting a high price $\left(\phi_{i}^{j} 1+\delta\right)$. Only computer spots will be realized $(q=\tilde{q}-\kappa)$, all consumers watch the programs, but only professionals matter for the broadcaster.

2. Setting an intermediate price $\left(\phi_{i}^{j} 1\right)$. Computer and hairdryer spots will be realized ( $q=\tilde{q}-2 \kappa)$ ). Professionals and housewives are equivalent from the point of view of the broadcaster, who could decide to broadcast comedies instead of sport programs (the audience composition would differ, not the broadcaster profit).

3. Setting a low price $\left(\phi_{i}^{j} 1-\delta\right)$. All consumers are "served" $(q=\tilde{q}-3 \kappa)$, and the broadcaster could "locate", indifferently, in any of the three program types.

The three revenue functions, corresponding to the three options above are:

$$
\begin{aligned}
& R 1(q)=\frac{\exp (\gamma q)}{\exp (\mu)+\exp (\gamma q)}(1+\delta) \\
& R 2(q)=\frac{\exp (\gamma q)}{\exp (\mu)+\exp (\gamma q)}+\frac{\exp (q)}{\exp (\mu)+\exp (q)} \\
& R 3(q)=\frac{\exp (\gamma q)}{\exp (\mu)+\exp (\gamma q)}(1-\delta)+\frac{\exp (q)}{\exp (\mu)+\exp (q)} 2(1-\delta)
\end{aligned}
$$

Comparing the revenue functions (7)-(9) with the (6), allow us to derive the following proposition:

Proposition 1. Program quality, for a monopolistic broadcaster who does not price discriminate in the market for advertising spots (and has increasing marginal costs), will be lower than the socially optimal level of quality, ${ }^{10}$ coinciding with the level chosen by a perfectly discriminating monopolist. Proof. The three revenue functions (9)-(11) will always be lower than the revenue function (8), for the same level of quality, and the marginal return of increased quality $\partial R / \partial q=\partial R / \partial \tilde{q}$ is also lower. Consider an hypothetical starting point, in which quality is the same in the two regimes. A profit maximizer would increase quality up to the point where marginal revenue equals marginal costs. Because a non discriminating broadcaster does not fully internalize the marginal benefits of a higher quality, optimal quality will be lower. In addition, identical quality, with different number of spots ( $n=3$ under discrimination, but $n \leq 3$ without discrimination) means that intrinsic quality is

10 Disregarding the consumers' utility of watching/listening programs. 
initially lower, already in the starting point.

The upper rows of Table 1 illustrates the findings above with a numerical example, in which: $\delta=0.5, \gamma=2, \kappa=0, \mu=1, t=1$, and marginal costs are linearly increasing with slope one. The table shows where the channel may be located, the advertising price, and the profit maximizing level of program quality, in the four regimes. In this case, if price discrimination is not possible, the best alternative is setting a unitary price for advertising, and broadcasting either sport or comedies.

Without price discrimination, some of the value of the advertisement is retained by the sellers. For example, if the price for spots (per viewer) is one, then a profit of $\phi_{P}^{S} \delta$ is retained by the computer sellers. If the per-viewer price is 1- $\delta$, computer sellers retain $\phi_{P}^{S} 2 \delta$, hairdryer sellers retain $\phi_{H}^{S} \delta$. If sellers' profits are added to the broadcaster profit, total profits amount to 1.006 in the first case, and to 1.085 in the second case. This means that advertising prices are "too high": a special kind of double marginalization effect.

Table 1 - A numerical example of monopolistic broadcasting 


\begin{tabular}{|c|c|c|c|c|c|c|c|c|c|}
\hline \multicolumn{3}{|c|}{ No. of Channels by Type } & \multicolumn{3}{|c|}{ Advertising Price by Type } & \multicolumn{3}{|c|}{ Program Quality by Ch. } & \multirow[t]{2}{*}{ Profit } \\
\hline$S$ & $C$ & $M$ & $S$ & C & $M$ & Ch1 & $\mathrm{Ch} 2$ & Ch3 & \\
\hline 1 & & & $0.5-1.5$ & & & 1.005 & & & 1.254 \\
\hline 1 & & & 1.5 & & & 0.733 & & & 0.593 \\
\hline 1 & (1) & & 1 & (1) & & 0.732 & & & 0.719 \\
\hline 1 & (1) & (1) & 0.5 & $(0.5)$ & $(0.5)$ & 0.475 & & & 0.463 \\
\hline 1 & 1 & & $0.5-1.5$ & $0.5-1.5$ & & 0.814 & 0.575 & & 1.601 \\
\hline 1 & 1 & (1) & 1.5 & 1.5 & $(1.5)$ & 0.653 & 0.127 & & 0.743 \\
\hline 1 & 1 & & 1 & 1 & & 0.499 & 0.499 & & 0.982 \\
\hline 1 & 1 & (1) & 0.5 & 0.5 & $(0.5)$ & 0.294 & 0.294 & & 0.668 \\
\hline 1 & 1 & & 1.5 & 1 & & 0.541 & 0.530 & & 0.895 \\
\hline 2 & & & $0.5-1.5$ & & & 0.552 & 0.552 & & 1.046 \\
\hline 2 & & & 1.5 & & & 0.366 & 0.366 & & 0.501 \\
\hline 2 & (2) & & 1 & (1) & & 0.355 & 0.355 & & 0.631 \\
\hline 2 & (2) & (2) & 0.5 & $(0.5)$ & $(0.5)$ & 0.221 & 0.221 & & 0.438 \\
\hline 1 & 1 & 1 & $0.5-1.5$ & $0.5-1.5$ & $0.5-1.5$ & 0.714 & 0.425 & 0.248 & 1.767 \\
\hline 1 & 1 & 1 & 1.5 & 1.5 & 1.5 & 0.568 & 0.089 & 0.089 & 0.842 \\
\hline 1 & 1 & 1 & 1 & 1 & 1 & 0.393 & 0.393 & 0.123 & 1.112 \\
\hline 1 & 1 & 1 & 0.5 & 0.5 & 0.5 & 0.208 & 0.208 & 0.208 & 0.798 \\
\hline 1 & 1 & 1 & 1.5 & 1 & 0.5 & 0.465 & 0.432 & 0.134 & 0.959 \\
\hline 1 & 1 & 1 & 1 & 1 & 0.5 & 0.415 & 0.415 & 0.123 & 1.034 \\
\hline
\end{tabular}

\subsection{Case \#2: Monopolistic broadcaster with two channels}

Consider now the case with two channels. Generalizing the reasoning above, it is natural to look first at the situation in which the broadcaster can discriminate and decides to locate the two channels in the first two program categories. Then, the revenue function, corresponding to (8) would be:

$$
\begin{aligned}
R\left(q_{S}, q_{C}\right) & =\left(\frac{\exp \left(\gamma q_{S}\right)}{\exp (\mu)+\exp \left(\gamma q_{S}\right)+\exp \left(q_{C}\right)}+\frac{\exp \left(q_{C}\right)}{\exp (\mu)+\exp \left(\gamma q_{S}\right)+\exp \left(q_{C}\right)}\right)(1+\delta) \\
& +\left(\frac{\exp \left(\gamma q_{C}\right)}{\exp (\mu)+\exp \left(\gamma q_{C}\right)+\exp \left(q_{S}\right)}+\frac{\exp \left(q_{S}\right)}{\exp (\mu)+\exp \left(\gamma q_{C}\right)+\exp \left(q_{S}\right)}\right) \\
& +\left(\frac{\exp \left(q_{S}\right)}{\exp (\mu)+\exp \left(q_{S}\right)+\exp \left(q_{C}\right)}+\frac{\exp \left(q_{C}\right)}{\exp (\mu)+\exp \left(q_{S}\right)+\exp \left(q_{C}\right)}\right)(1-\delta)
\end{aligned}
$$

Like in the previous case, $q_{S}=q_{1}-t / 12$ and $q_{C}=q_{2}-t / 12$.

Here, however, there is an alternative possibility. Both channels could also be located in one 
segment type. For the same reasons discussed above, if this happens, then the selected program type must be "sport". Increasing the number of channels in a category, for a given level of quality of the programs, increases the intra-type differentiation and the expected quality of the type. Because of Lemma 2, Lemma 5, and symmetry, $q_{S}=q_{1}-t / 48=q_{2}-t / 48$. Therefore, if it is important to attract as many professionals as possible with sport programs (for example, because there is strong correlation between consumer groups and program types, and professionals buy profitable goods), then the monopolist could either (a) increase the quality $q$ of the sport programs, or (b) increase the number of sport channels.

In the example reported in Table 1, multiple sport channels generate less profits than two separate channels, one for sport and the other one for comedies. This is not a general result, as the reverse may occur if marginal costs of quality are higher, the premium $\delta$ on professionals is higher, the correlation factor $\gamma$ is higher, or the $t$ parameter is higher.

Also, notice that the quality of sport programs with two channels is lower than the one with one channel. This result is due to intra-brand competition, and it is similar to the case in which a multiproduct firm, selling substitutable goods, keeps prices higher than a single-product firm.

The other rows in the central part of Table 1 display the numerical results associated with the regime of no price discrimination. Again, we can have three alternative price strategies (high, intermediate, low), this time for the two cases of separate types or multi-channel type. Notice that:

- Quality is generally lower than in the case of price discrimination, for the same reason pointed out in Proposition 1 (marginal revenue is lower, marginal benefits of higher quality are not fully internalized);

- When the price for advertising is not high, there can be equivalent type locations for the broadcaster, keeping the profit unchanged, but affecting the audience composition;

- With these parameter values, the maximum profit is achieved with intermediate prices for advertising, in both cases (two types, one type with two channels);

- The lower the price for spots in the programs, the lower the quality of the programs. This is again a consequence of lower marginal revenue.

In the middle of Table 1, a special case of indirect price discrimination is also considered. It is assumed that the broadcaster charges different prices for advertising, not on the basis of the content of the spots, but on the basis of the channel in which the spots are given. Of course, this strategy makes sense only if the two channels are associated with different types, like sport and comedies. Therefore, consider a situation in which spots on the sport channel are relatively expensive, they deal only with computers, as the audience has a majority of professionals, and spots on the comedy channel are cheaper, dealing with both hairdryers and computers, for an audience in which the majority is housewives. In this numerical experiment, quality turns out to be higher, but profits turn 
out to be lower, than in the case of equal intermediate prices for advertising in both channels.

\subsection{Case \#3: Monopolistic broadcaster with three channels}

Let us examine now the case with three channels, where we focus on the situation in which the three channels broadcast different program types. Again, we distinguish between: perfect price discrimination (based on advertisement content), no price discrimination (same price for advertising, per viewer, independently of channel and content), and partial-indirect price discrimination (different prices by channel). Results of the illustrative example are reported in the bottom part of Table 1.

Results are in line with previous findings. In particular:

- Quality is lower without price discrimination, and decreasing in advertising prices;

- Indirect price discrimination is not superior to no price discrimination at all. ${ }^{11}$

Furthermore, observe that total profits are increasing in the number of channels, although with decreasing returns. This suggests that the model could be easily extended, for example by introducing fixed costs, to cover the instance in which the number of channels is not predetermined, but it is optimally chosen (to maximize profits) by the monopolistic broadcaster.

3.6 Case \#4: One channel for the incumbent broadcaster, one channel for a competitive entrant, with different program types

Suppose that an entrant starts broadcasting with a new channel, with different type of programs, in competition with a single-channel incumbent. Equivalently, a two-channels incumbent sells her secondary channel to an entrant. The incumbent has a first mover advantage, meaning that she will retain the sport channel, whereas the entrant will provide comedies.

Under price discrimination, the revenue functions for the incumbent and the entrant firms are, respectively:

$$
\begin{aligned}
R_{I}\left(q_{S}, q_{C}\right) & =\left(\frac{\exp \left(\gamma q_{S}\right)}{\exp (\mu)+\exp \left(\gamma q_{S}\right)+\exp \left(q_{C}\right)}\right)(1+\delta) \\
& +\left(\frac{\exp \left(q_{S}\right)}{\exp (\mu)+\exp \left(\gamma q_{C}\right)+\exp \left(q_{S}\right)}\right) \\
& +\left(\frac{\exp \left(q_{S}\right)}{\exp (\mu)+\exp \left(q_{S}\right)+\exp \left(q_{C}\right)}\right)(1-\delta)
\end{aligned}
$$

11 This result is not general. In particular, it is due to the discontinuous nature of the demand curve for advertising. 


$$
\begin{aligned}
R_{E}\left(q_{S}, q_{C}\right) & =\left(\frac{\exp \left(q_{C}\right)}{\exp (\mu)+\exp \left(\gamma q_{S}\right)+\exp \left(q_{C}\right)}\right)(1+\delta) \\
& +\left(\frac{\exp \left(\gamma q_{C}\right)}{\exp (\mu)+\exp \left(\gamma q_{C}\right)+\exp \left(q_{S}\right)}\right) \\
& +\left(\frac{\exp \left(q_{C}\right)}{\exp (\mu)+\exp \left(q_{S}\right)+\exp \left(q_{C}\right)}\right)(1-\delta)
\end{aligned}
$$

Comparing (13) and (14) with (12), the following result can be readily established:

Proposition 2. Program quality in two channels, owned by independent operators, will be higher than in the case of single ownership.

Proof. Notice that: $R\left(q_{S}, q_{C}\right)=R_{I}\left(q_{S}, q_{C}\right)+R_{E}\left(q_{S}, q_{C}\right)$

$$
\begin{array}{ll}
\frac{\delta R_{I}\left(q_{S}, q_{C}\right)}{\delta q_{S}}>0 & \frac{\delta R_{I}\left(q_{S}, q_{C}\right)}{\delta q_{C}}<0 \\
\frac{\delta R_{E}\left(q_{S}, q_{C}\right)}{\delta q_{C}}>0 & \frac{\delta R_{E}\left(q_{S}, q_{C}\right)}{\delta q_{S}}<0
\end{array}
$$

So, market externalities are at work, and the marginal benefits of higher quality are greater than in the case of monopolistic ownership. This result is perfectly analogous to the one bringing about lower prices in competition, with differentiated products.

Also:

Proposition 3. Program quality in the entrant channel will be lower than the quality in the incumbent channel, if price discrimination in the advertising market is possible.

Proof. Returns on quality are higher for the incumbent. To see this, switch $q_{S}$ with $q_{C}$, and vice versa, in the entrant revenue function (14), and compare with (13). For identical levels of quality, revenue will be lower for the entrant. Marginal revenue, that is, the incentive to raise quality, will be lower as well.

These findings are confirmed by the numerical results reported in Table 2. This table shows the equilibrium levels of quality, and profits, obtained in the regimes of duopolistic competition, using the same parameter values of Table 1 . The scenario with two independent channels is considered in the upper part of the table, for the two cases of perfect price discrimination and no discrimination, with unitary price. Notice that the incumbent advantage vanishes without price discrimination, as the two revenue functions would then be identical.

Table 2 - A numerical example of duopolistic broadcasting 


\begin{tabular}{|ccc|c|c|c|c|c|c|c|c|}
\hline \multicolumn{2}{c}{ Ownership } & \multicolumn{2}{c|}{ Advertising Price by Type } & \multicolumn{3}{c|}{ Program Quality by Ch. } & \multicolumn{2}{c|}{ Profit } \\
S & $\boldsymbol{C}$ & $\boldsymbol{M}$ & $\boldsymbol{S}$ & $\boldsymbol{C}$ & $\boldsymbol{M}$ & Ch1 & Ch2 & Ch3 & I & E \\
\hline \hline I & E & & $0.5-1.5$ & $0.5-1.5$ & & 1.067 & 0.920 & & 0.833 & 0.673 \\
\hline I & E & & 1 & 1 & & 0.694 & 0.694 & & 0.473 & 0.473 \\
\hline \hline I & I & E & $0.5-1.5$ & $0.5-1.5$ & $0.5-1.5$ & 0.868 & 0.528 & 0.633 & 1.199 & 0.486 \\
\hline I & I & E & 1 & 1 & 1 & 0.476 & 0.476 & 0.293 & 0.777 & 0.314 \\
\hline
\end{tabular}

\subsection{Case \#5: One channel for the incumbent broadcaster, one channel for a competitive entrant,} with the same program type

Of course, the entrant could also enter in the same program category in which the incumbent is already operating. The potential advantage of doing so is that the entrant could benefit from acting inside the richest segment, but the disadvantages are that (1) the sub-market has to be shared with the incumbent, and (2) this will trigger intra-type quality competition.

By increasing the quality of the (sport) programs, a broadcaster increases the overall expected quality of sport channels, but she will also gain more consumers within the sport segment. Inside the segment, consumers are ideally located in a circle with unitary perimeter, homogeneously, whereas the channels are located at two opposite locations (Lemma 1). If the channels provide programs with the same quality, the market is equally split. If one channel provides higher quality programs, her market area will be larger than one half, and dependent on the quality differential (Lemma 3). If the quality differential is higher than $t / 4$, a single channel gets the whole market.

Equilibrium in the sub-market can be described as a Nash equilibrium in a game of quality competition. Figure 1 displays the reaction functions of the two firms in the program quality space. If the competitor provides low-quality programs, it will be sufficient to provide the monopolistic level of quality, since the market would then become monopolistic. If the competitor quality is sufficiently high, a firm may want to provide higher quality levels, so as to attract more consumers than the rival. If the marginal production cost of quality is not too high, and consumers can easily switch from one channel too another (low differentiation in consumers' tastes), then a firm may be willing to get the whole sub-market. This can be achieved by supplying quality $t / 4$ higher than the competitor. ${ }^{12}$ Since the same reasoning can be applied to the other firm, the outcome is a "quality race", in which the two firms leapfrog each other in terms of quality levels. Eventually, since marginal costs of quality are increasing, a firm may find not profitable to get the whole market, and a Nash equilibrium could be found, in which the (symmetric) firms equally share the market with

12 Even higher quality is expensive to produce and brings no gains in terms of intra-type market area. It could attract more external consumers toward sport programs, but this is not sufficient to justify the cost increase, as quality is already above the monopolistic optimum. 
identical quality levels.

The problem with this candidate equilibrium (point $\mathrm{N}$ in Figure 1), is that profits may be negative. This is the case for parameter values used in the numerical examples of Tables 1 and $2 .{ }^{13}$ In Figure 1, two isoprofit curves are also drawn, representing the zero profit locus for the two firms. Therefore, the parts of the reaction function above points $\mathrm{Z} 1$ or $\mathrm{Z} 2$ should not be considered: there is no Nash equilibrium.

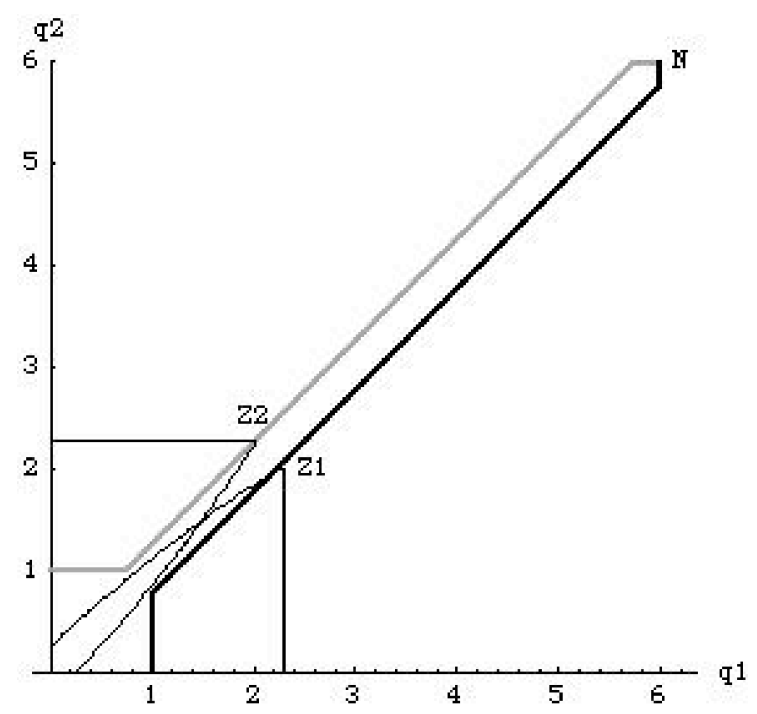

Figure 1 -Reaction functions for the quality competition sub-game

The lack of a Nash equilibrium refers to the case in which the decision of locating in the same category of programs has already been taken. We can therefore interpret this result as suggesting that broadcasters will never locate in the same segment, anticipating that quality competition would be too tough.

This happens when marginal costs of quality are low, and/or consumers are little differentiated inside a category of programs. In our numerical example, marginal costs are linearly increasing, with a unitary slope factor. If this factor is increased to 10 , an equilibrium exists with quality set at 0.225 and profits amounting to 0.246 . Analogously, if the "transport cost" parameter $t$ (representing the degree of differentiation in consumers' tastes for sport programs) is increased from 1 to 4 , an equilibrium is found with quality at 1.203 , and profits at 0.255 .

3.8 Case \#6: Two channels for the incumbent broadcaster, one channel for a competitive entrant, with different program types

Let us consider a natural extension of the case of entry with different program types, analyzed above. This time, however, the incumbent owns two channels (sport and comedy) and the entrant

13 Price discrimination in the advertising market is assumed. 
operates with the residual type (music). Results for the numerical example are reported in the bottom part of Table 2 .

Whereas the incumbent takes into account the cross-effects on profits of higher quality, between her own channels, the entrant behaves competitively and disregards any negative effect of higher quality on the competitor's profit. With price discrimination in advertising, there are incentives for keeping quality high in those channels associated with high-spending consumers, but these incentives are lower the greater the number of channels owned by the same firm. Combining these two effects together, we can see that quality in the music channel may be higher than in the comedy channel.

Quality will also be lower if broadcasters cannot price-discriminate. If an intermediate price is chosen for ad spots, the incumbent will select the same quality level for her channels, higher that that of the entrant.

\section{Discussion and Model Extensions}

Vertical and horizontal differentiation are competitive strategies in a broadcasting industry, based on free access and advertising. The model illustrated in the previous section highlights how the competitive game unfolds, under various scenarios of ownership and price discrimination in the market for advertising services.

In the cases considered above, the ownership structure is given. This corresponds to a situation in which market entry is controlled by a regulator. This regulator could, in principle, compare the various equilibria, and choose an optimal market structure. This choice would then depend on a number of critical factors: the amount and type of price discrimination in advertising, the correlation between formats and audience composition, the relative profitability of the different market segments, and diseconomies of scale in program quality.

The model could be extended, without major difficulties, to consider situations in which the number of channels can be chosen by the operators, or the case of free entry with fixed costs (monopolistic competition).

The model differs from most other models in the literature, because it provides a more realistic representation of advertising, which allows focusing on the relationship between media markets and advertising markets. Nonetheless, the modeling of advertising is still quite elementary.

For example, the existence of a single producer for each type of good was assumed, with full information and homogeneity in consumer tastes. In this setting, the willingness to pay for advertisement expresses the social value of advertising. As a consequence, a perfectly discriminating broadcaster could fully appropriate the social surplus, and select the socially optimal level of quality for the programs. 
The modeling of the advertising sub-market could be improved in a variety of ways, with possible implications for the model results. A distinction could be drawn, for example, between informative, persuasive, and complementary advertising (Bagwell (ibid.)). The introduction of multiple producers and advertisers would also open up the possibility that the willingness to pay for advertisement exceeds the social value of advertising, because of business stealing among competing producers. In this case, the absence of price discrimination, preventing full expropriation of the advertisers' willingness to pay by the broadcaster, could be socially beneficial.

Other model improvements could be easily devised on the media market. Even if the model considers a relatively complex, multidimensional competition among channels, there are other features which have been left out like, for instance, time scheduling. Perhaps the most important aspect that could be considered is the possible non-independence of quality costs. Very often, channels compete for limited resources: talents, "stars", special events. This would imply that quality costs depend on quality levels selected by other channels, competing or not.

\section{Conclusion}

This paper has analyzed, through a specific model: (i) the effects of price discrimination by advertisers and (ii) the effects of audience composition on advertising profitability and the ability to price discriminate. The link between between format choice and quality competition, on one hand, and price discrimination and audience composition has been highlighted.

Quality and format choice depend on marginal surplus internalization. Price discrimination may help broadcasters to get more marginal benefits of higher program quality, and this effect may be especially important when consumers are heterogeneous in terms of (a) profitability, (b) correlation between program type and audience composition.

\section{Acknowledgements}

Marco Gambaro introduced me to this topic, and helped me with various suggestions on earlier drafts of this paper. Two anonymous referees provided valuable remarks, pointed out errors and suggested alternative formulations for the model. The usual disclaimer applies.

\section{References}

Anderson, S.P. and Coate, S. (2000), Market Provision of Public Goods: the case of Broadcasting, NBER working paper n. 7513.

Anderson, S.P. and Coate, S. (2005), "Market Provision of Broadcasting: A Welfare Analysis", Review of Economic Studies, 72, 947-972.

Bourreau, M. (2003), "Mimicking vs. Counter-programming Strategies for Television Programs", Information Economics and Policy, 15, 35-54. 
Dukes, A. (2004), "The Advertising Market in a Product Oligopoly", The Journal of Industrial Economics, 52, 327-348.

Beebe, J. (1977), "Institutional Structure and Program Choices in Television Markets", Quarterly Journal of Economics, 91, 15-37.

Berry, S. and Waldfogel, J. (1999a), "Free Entry and Social Inefficiency in Radio Broadcasting”, Rand Journal of Economics, 30, 397-420.

Berry, S. and Waldfogel, J. (1999b), Mergers, Station Entry, and Programming Variety in Radio Broadcasting, NBER working paper n. 7080.

Ofcom (2004), Economic Analysis of the TV Advertising Market (report by PwC).

Papandrea, F. (1997), "Modelling Television Programming Choices", Information Economics and Policy, 9, 203-218.

Roson, R. (2005), “Two-Sided Markets: a Tentative Survey", Review of Network Economics, 4, 142-160.

Spence, M. and Owen, B. (1977), "Television Programming, Monopolistic Competition and Welfare", Quarterly Journal of Economics, 91, 103-126.

Steiner, P. (1952), "Program Patterns and Preferences, and the Workability of Competition in Radio Broadcasting", Quarterly Journal of Economics, 66, 194-223. 


\section{Appendix}

\section{Proof of Lemma 1}

Consumers are uniformly distributed in a circle with unitary perimeter. Without lack of generality, assume that firm (channel) 1 is located at point zero, whereas firm 2 is located at distance $x$ from the first firm (measuring the distance clockwise, for example).

Consider a two-stage game in which firms decide upon location, and subsequently upon quality levels. Consumers go to the firm providing the highest net utility, defined as a difference between quality level and transport costs. We consider here quadratic transport costs, but the case can be easily generalized.

Each firm, for example firm 2, is active on two sub-markets, to the left and to the right of her location. The boundaries of the two market areas can be easily identified by considering the marginal consumer, indifferent in her choice between the two firms. This allows us to state the demand of firm 2, located in $x$ and providing quality $q_{2}$, when firm 1 provides quality $q_{1}$, as:

$$
D_{2}\left(q_{1}, q_{2}, x\right)=\frac{1}{2}+\frac{q_{2}-q_{1}}{2 t x}+\frac{q_{2}-q_{1}}{2 t(1-x)}
$$

Profits of firm 2 are given by the difference between $D_{2}$ and quality production costs. Taking as given location $x$ and competitor's quality $q_{1}$, the optimal $q_{2}$ is found by equating marginal revenue (constant) with marginal cost (increasing, to satisfy the second order condition). If, for example, production costs are quadratic $\left(C(q)=c q^{2} / 2\right)$, then:

$$
q_{2}^{o}=\frac{1}{2 \operatorname{ct} x(1-x)}
$$

Since the two firms are symmetric, they must end up doing the same choices. Therefore, irrespective of the level of quality, the market is always equally split. The profit maximizing location is the one which brings about the lowest quality in equilibrium. This is obtained by maximizing the denominator of (A2), which gives $x=1 / 2$, the result of maximal distance/differentiation. 